\title{
Getting Involved In Volunteer Work Could Protect Against Relapse among Detoxified Opiate Patients: A Six Months Follow Up Study
}

\author{
Ahmed Rady ${ }^{1,+}$, Tarek Moloukhiya', Osama Elkholy', Enas Shawky²
}

\begin{abstract}
Background and objectives: Drug abuse is a major mental health concern. Though diverse psychological interventions are available such as cognitive behavioral, psychodynamic, hypnotherapy, group, family, community based and Motivation enhancement psychotherapy as well as 12 step model of Narcotics Anonym NA, but still high relapse rates are reported in literature. Our study aims at assessing an innovative approach based on shifting focus of attention from self to overcome obsessive self-concern, which can be partly categorized under community based interventions
\end{abstract}

Methods: 60 opiate addict patients were recruited within one week after hospitalized detoxification at Mamoura Psychiatric Hospital. Active phase (3 months): 30 patients went through two hours structured cognitive behavioral CBT group therapy (max. 10 patients in a group) twice weekly and the other 30 patients went through shifting focus approach by implicating them in volunteer act at Alexandria University Hospital Hepatology department for 2 hours volunteer work twice weekly with a weekly group meeting (max. 10 patients in a group) with psychotherapist, who carried out group animation focusing on experience exchange in a supportive encouraging relational frame. Follow up phase (3 months): both groups were seen on monthly basis as booster session keeping the same psychotherapeutic modality frame. Both active and follow up phases were carried out on outpatient basis. Abstinence was assessed by urine screening on monthly bases and quality of life was psychometrically assessed

Results: Both groups were balanced in terms of age, marital status, age at onset of drug abuse and base line score of quality of life scale QLS. After 6 months, no difference was found between both groups in terms of abstinence rate, QLS score and increment of QLS score ( $p>0.05)$

Conclusion: Shifting focus approach by implicating detoxified patients in regular volunteer act reveals as efficacious as structured group CBT approach in a non-inferiority study design

\section{Keywords}

Opiate, CBT, Psychotherapy, Community based therapy, Relapse, Volunteer, Addiction, Substance misuse

\footnotetext{
'Department of Psychiatry, Alexandria University School of Medicine, Egypt

2El-Mamoura Psychiatric Hospital, Alexandria, Egypt

${ }^{+}$Author for correspondence: Ahmed Rady, MD, 29, Nabi Daniel St, Alexandria 21131 - Egypt, Tel: +2 01282441053; email: dr_ahmed_ rady@yahoo.fr
} 


\section{Introduction}

Data coming from the epidemiological modeling undertaken in global burden of disease GBD 2010 produced novel results about levels of dependent drug use across the globe; Opioid and amphetamine dependence were the two most common forms of illicit drug dependence globally in 2010; 15.4 million and 17.2 million estimated cases, respectively. There were 13.1 million cannabis-dependent and 6.9 million cocaine-dependent persons. Males formed the majority of cases, $64 \%$ each for cannabis and amphetamines and $70 \%$ each for opioids and cocaine [1]. The overall burden of disease is calculated using the disability-adjusted life year DALY, a measure that combines years of life lost due to premature mortality with years of life lost due to time lived in less than full health, Drug use disorders directly accounted for 20.0 million DALYs in 2010 ( $15.3-25.4$ million). This was $0.8 \%$ of global all-cause DALYs. There was an increase of $52 \%$ from estimates for 1990 . Opioid dependence accounted for the highest proportion $46 \%$ of illicit drug burden ( 9.2 million DALYs), Cocaine dependence accounted for the smallest burden (5.5\% of illicit drug burden) [2].

Psychosocial treatments for substance use disorders attempt to counteract compulsive substance use by bringing about changes in patients' behaviors, thought processes, affect regulation, and social functioning. Although the techniques and theories of therapeutic action vary widely across the different approaches reviewed below, they all address one or more of a set of common tasks as enhancing motivation to stop or reduce substance use, teaching coping skills, changing reinforcement contingencies, fostering management of painful affects and enhancing social supports and interpersonal functioning [3].

A growing body of efficacy data from controlled clinical trials suggests that psychotherapy is superior to control conditions as a treatment for patients with a substance use disorder. However, no particular type of psychotherapy has been found to be consistently superior when compared with other active psychotherapies for treating substance use disorders, even comparatively brief psychotherapies appear to have durable effects among patients with a substance use disorder [4-6].

CBT is efficacious in reducing illicit substance use and achieving a wide range of other treatment goals. The benefits of CBT in combination with drug counseling are equivalent to those of drug counseling alone or drug counseling plus supportive-expressive psychotherapy in patients with low levels of psychiatric symptoms; however, in the presence of higher degrees of depression or other psychiatric symptoms, supportive-expressive therapy or CBT has been shown to be much more effective than drug counseling alone [7,8]. CBT may also help reduce other target symptoms or behaviors e.g., HIV risk behaviors in opioid-using individuals. Group based relapse prevention therapy, when combined with self-help group participation, may also help recently detoxified patients reduce opioid use and criminal activities and decrease unemployment rates $[9,10]$.

Community Reinforcement Approach (CRA) is a comprehensive cognitive-behavioral program for treating substance abuse problems. It is based on the belief that environmental contingencies can play a powerful role in supporting or discouraging drinking or drug-using behavior. As such, it utilizes familial, social, recreational, and occupational reinforcers to aid clients in the recovery process. The goal is to rearrange multiple aspects of an individual's "community" so that a clean and sober lifestyle is more rewarding than one that is dominated by alcohol an drugs [1113].

CRA therapists combine a variety of treatment strategies: Building Motivation This process involved the identification of positive reinforcers (e.g., praise and shared pleasant events) that could serve as effective incentives for the client to change his or her behavior. The CRA therapist also reviews with the client the current and future negative consequences of the client's drinking patterns [14]. Initiating Sobriety The therapist moves on to setting goals for achieving abstinence. Because many clients are reluctant to commit themselves to immediate total and permanent abstinence, a procedure called sobriety sampling can be helpful This procedure uses various counseling strategies to negotiate intermediate goals, such as a trial period of sobriety. For example, the therapist may encourage the client to try not drinking for 1 month, to see how it feels and to learn more about the ways in which he or she has been depending on alcohol $[15,16]$. Analyzing Drinking Patterns CRA involves a thorough functional analysis of the client's drinking patterns. This analysis helps identify situations in which drinking is most likely to occur (i.e., high-risk situations) as well as positive consequences of alcohol consumption 
that may have reinforced drinking in the past. This step, which is often underemphasized in cognitive behavioral therapy, is useful in individualizing treatment and in determining specific treatment components, or modules, that are most likely to be successful for a particular client. [17]. Increasing Positive Reinforcement Once the analysis of the client's drinking patterns is completed, both the client and therapist select appropriate modules from a menu of treatment procedures to address the client's individual needs. Many of these treatment modules focus on increasing the client's sources of positive reinforcement that are unrelated to drinking. For example, as people become increasingly dependent on alcohol, their range of nondrinking activities (e.g., hobbies, sports, and social involvement) narrows substantially, resulting in increasing isolation Consequently, an important component of recovery for the drinker is to reverse this isolation process by becoming involved with other nondrinking people and by increasing the range of enjoyable activities that do not involve drinking [18].

Though of diverse psychotherapeutic modalities are available for substance misuse and addictive behavioral patterns but high relapse rate is still representing a great challenge to mental health professionals [19-23].

Our study aims at assessing an innovative therapeutic frame that can be partially subcategorized under community based interventions for relapse prevention.

\section{Subjects and Methods}

Study has been approved by the ethics committee of Alexandria University Medical School. All participants gave written consent and purpose of the study was explained to them. 60 male patients were recruited after discharge from El-Mamoura Psychiatric hospital following successful detoxification from heroin. Age ranged 16-40 yrs old, patients with chronic debilitating illness or mental subnormality were excluded. Patients only addict to opiates before the study were included. Structured questionnaire to collect demographic data and clinical data relevant to drug misuse as age at onset of addiction, marital status and number of previous relapses.

Quality of life was quantitatively measured using Quality of Life Scale QOLS which has 16 items each rated from 1 to 7 , a total score is calculated by summing up all items. (24) All participants had a baseline score and at the end of the study

Patients were randomly assigned to one of 2 groups.

\section{- Phase I (the active phase)}

It lasted 3 months, carried out on outpatient basis

Group $1 \quad(\mathrm{~N}=30)$ : Shifting focus approach based on community service volunteer work, they were encouraged to actively participate in 2 hours volunteer work twice weekly at Alexandria University Hospital, department of hepatic diseases. They met once weekly with the psychotherapist who animated supportive group therapy sessions of 2 hours, each group 10 patients maximum, it was a closed group where the role of therapist was to facilitate exchange of experiences and encouragement of their volunteer work.

Group 2 ( $N=30)$ : CBT group, they had twice weekly group cognitive behavioral psychotherapy sessions of 2 hours duration, cognitive behavioral therapeutic frame, sessions them was structured as follows, week 1 psycho education and cycle of change, week 2 functional analysis of common risk situations, maladaptive thoughts and behavior, week 3 analysis of external and internal risky situations in terms of relapse, week 4 structured of daily activities, week 5 control of emotions and psychological stress with relaxation techniques, week 6-8 cognitive restructuring of automatic thoughts and patients were trained to do their action planer, week 9-10 assertiveness and self-confidence, week 11 problem solving skills and lastly week 12 Going briefly through previously acquired skills and concepts assuring good understanding of patients

\section{- Phase II (follow up phase)}

Group $1(\mathrm{~N}=30)$ : Shifting focus approach based on community service volunteer work, had booster 2 hours monthly group session, same closed group and supportive therapeutic frame were maintained

Group $2(\mathrm{~N}=30)$ : CBT group, had booster 2 hours monthly group session, same closed group and cognitive behavioral therapeutic frame were maintained

Patients did urine screening for drugs of abuse before therapy, at the end of active therapy phase and at the end of the study. Any patient who relapses is counted as failure of the therapeutic modality used. 
Patients who don't attend for 3 consecutive psychotherapy sessions were considered dropped out

\section{- Statistical analysis}

After data collection, they were fed into computer after coding using Statistical Package for Social sciences SPSS version 11.5 for data analysis and tabulation. Descriptive analysis were done, parametric values arithmetic mean, median and standard deviations were calculated, Chi square test was used as non-parametric testing tool. Type one statistical error was set $<0.05$

\section{Results}

Both groups were balanced in terms of age, marital status, socioeconomic status, age of onset of drug abuse baseline quality of life scale QOLS ( $p>0.05$ ) however group 1 had significantly more number of previous relapses Table 1 .

At the end of the study both groups were compared in terms of abstinence rate, quality of life score and increment in quality of life scale compared to baseline Table 2 .

\section{Discussion}

In our study, we evaluated an innovative psychological intervention for relapse prevention among detoxified patients with substance misuse disorder. It can be categorized under community based interventions though patients rather than the community did play the active role. In our non-inferiority comparative cohort study, no statistical difference was found between both groups in terms of abstinence rate as well as improvement in quality of life.

\section{- What does really work in psychotherapy?}

Many authors evoked the common factor theory for psychotherapeutic modalities. Since diverse psychotherapies do reveal efficacy for the same psychopathology then it sounds coherent that they do share common factors. Relational-ProceduralPersuasion RPP model is an example. In this model, common factors between theoretically different psychotherapeutic approaches share as common base: A good relational frame, rituals in the form of periodicity of meeting (sessions) and a way to persuade a patient and serving as a social model to the patient by showing consistency and expert voice $[25,26]$. Another model of common factor theory among other theories is the methodological principles and skills MPS model, where authors evoke similarity among different therapies in terms of therapeutic principles such as construction of empathic validating relation, a sort of exposure to problem and creating an interpersonal learning experience [26,27].

Though CBT received a high level of empirical evidence in literature, most of studies are comparing pharmacotherapy in one group

\begin{tabular}{|c|c|c|c|}
\hline & $\begin{array}{l}\text { Group } 1(\mathrm{~N}=30) \\
\text { Shifting focus approach based on } \\
\text { community service volunteer work }\end{array}$ & $\begin{array}{l}\text { Group } 2(\mathrm{~N}=30) \\
\text { Structured Cognitive behavioral } \\
\text { psychotherapy }\end{array}$ & Statistical test \\
\hline Age in years & $32.87 \pm 6.3$ & $30.53 \pm 4.9$ & $\mathrm{t}=1.6$ \\
\hline $\begin{array}{l}\text { Marital status } \\
\text { Single } \\
\text { Married }\end{array}$ & $\begin{array}{l}\text { No. } \\
22 \\
8\end{array}$ & $\begin{array}{l}\text { No. } \\
21 \\
9\end{array}$ & $X^{2}=0.082$ \\
\hline Age at onset of abuse & $13.4 \pm 1.16$ & $13.7 \pm 0.7$ & $\mathrm{t}=1.21$ \\
\hline No. Of previous relapses & $4.7 \pm 1.06$ & $4.03 \pm 0.81$ & $\mathrm{t}=2.746^{*}$ \\
\hline Baseline QOLS score & $13.25 \pm 3.13$ & $13.29 \pm 1.74$ & $t=0.041$ \\
\hline \multicolumn{4}{|l|}{${ }^{*} p<0.05$} \\
\hline
\end{tabular}

\begin{tabular}{|c|c|c|c|}
\hline & $\begin{array}{l}\text { Group } 1 \text { ( } N=30 \text { ) } \\
\text { Shifting focus approach based on } \\
\text { community service volunteer work }\end{array}$ & $\begin{array}{l}\text { Group } 2(\mathrm{~N}=30) \\
\text { Structured Cognitive behavioral } \\
\text { psychotherapy }\end{array}$ & Statistical test \\
\hline Quality of life scale QOLS score & $60.5 \pm 7.32$ & $65.43 \pm 7.94$ & $t=1.934$ \\
\hline $\begin{array}{l}\text { Increment of QOLS score } \\
\text { Compared to baseline score }\end{array}$ & $47.25 \pm 7.53$ & $52.14 \pm 7.6$ & $t=1.948$ \\
\hline $\begin{array}{l}\text { Relapse rate } \\
\text { Relapsed } \\
\text { Not relapsed }\end{array}$ & $\begin{array}{l}\text { No. } \\
14 \\
16\end{array}$ & $\begin{array}{l}\text { No. } \\
9 \\
21\end{array}$ & $X^{2}=1.763$ \\
\hline
\end{tabular}


with pharmacotherapy combined to $\mathrm{CBT}$ treatment in another group. A very interesting Meta analytic study, attempted to select only studies where CBT in one arm was compared to nonspecific psychological intervention in the other arm conducted by a research group at Stobhill hospital in Glasgow. It's a metaanalysis study for comparative studies evaluating cognitive behavioral therapy to control group receiving nonspecific psychological intervention and they concluded that cognitive behavioral therapy is not statistically significantly different from nonspecific intervention! A strong finding that really raises the question whether delivering a good carell rather than adopting a specific therapeutic strategy is the main determinant factor for therapeutic efficacy. What does really work in psychotherapy is a complicated question that inspired lot of experts in psychotherapy field [28].

\section{- Eastern and western philosophy of psychotherapy}

Eastern philosophy constructs as Buddhist practices where psychological suffering results from obsessive self-concern and one has to discover himself through sublimating his spirit and finding self in helping others rather than focusing on self needs. A psychological stress is seen as a passing cloud that one has to observe as such! Accepting its existence with no moral judgment [29-32].

This philosophical concept is not specific to Buddhism, but rather present in many eastern born spiritual religious practices. Sufi practice and deep prayers in Sufi Muslim communities [33-35], and monastic practices in Christianity where one isolates himself in monastery for deep worshiping, contemplation and meditation on self, as well as other major spiritual religious confessions like Hinduism and other old eastern religions [36,37].

Meditation and Meditative practices are in fact based on these spiritual practices that begun in eastern born religions, and they are philosophically different from recent western born psychotherapies inspired by renaissance philosophies, where the therapeutic process is self-centered, e.g. functional analysis of CBT where on observe himself for automatic thoughts and maladaptive behavior, try to question those thoughts and judge them with various specific techniques. Psychodynamic with its linear causality model, based on analyzing one's past and judging it's causality relationship with present problem so to understand how one's psychic apparatus worked improperly generating psychopathology. That's why it's considered insight oriented approach [38].

Differences between east and west have always been inspiring to film makers, philosophers, psychotherapists, evolution psychologists and transcultural psychiatrists [39-40]. Empirical evidence coming from literature supporting better efficacy when integrating eastern and western philosophical approaches to psychotherapy, mindfulness based CBT is an excellent example of such integration $[41,42]$.

\section{- Rational of shifting focus approach by community service volunteer work}

Though it can be categorized partially under community based intervention, but a crucial difference is that in this approach, the patient rather than the society is playing the active role. In fact, no instructions have been given to other workers in the general hospital where patients were volunteering. This innovative approach adopted in our study reflects a challenge to understand current therapeutic approaches, being based on overcoming the obsessive self-concern which is in our opinion a major contributing factor to psychopathology and mental suffering.

\section{Conclusion}

Volunteer work and absorbing oneself in helping others can help patients with addictive behavior to keep abstinent and represents an effective approach to guard against relapse

\section{Limitation}

Larger samples are needed in future research to justify the extrapolation of our results, and a longer duration of follow up is needed to further confirm stability of outcomes over time. All recruited patients were adult men and assessing a gender sensitive difference in response cannot be made. Participants were not assessed in terms of educational status or IQ

\section{Recommendations}

Adding another supporting psychological intervention, particularly, spiritual therapy to both arms may enhance abstinence rate, at least, as a provisional assumption that has to be verified and addressed in future research

\section{Conflict of Interest disclosure}

No conflict of interest to be declared 


\section{References}

1. Prince M, Patel V, Saxena S, et al. No health without mental health. Lancet 370(1), 85977 (2007).

2. Degenhardt $L$, Hall W. Extent of illicit drug use and dependence, and their contribution to the global burden of disease. Lancet 379(1), 55-70 2012.

3. Rounsaville BJ, Carroll KM, Back S. Individual psychotherapy, in Substance Abuse: A Comprehensive Textbook. 4th ed. Lippincott: Williams \& Wilkins,. pp 653-70 (2004).

4. Rounsaville B. Can psychotherapy rescue naltrexone treatment of opioid addiction? In: Onken L, Blaine J, (eds). Potentiating the Efficacy of Medications: Integrating Psychosocial Therapies With Pharmacotherapies in the Treatment of Drug Dependence. Rockville, MD: National Institute on Drug Abuse,. pp. 37-52 ( 1995).

5. Greenstein R, Fudala PJ, O'Brien CP. Alternative pharmacotherapies for opiate addiction. In: Lowinson JH, Ruiz P, Millman RB, Langrod JG, (eds). Substance Abuse: A Comprehensive Textbook. 3rd ed. New York: Williams \& Wilkins,. pp 415-24 (1997).

6. Carroll KM, Sinha R, Nich C, et al. Contingency management to enhance naltrexone treatment of opioid dependence: a randomized clinical tria of reinforcement magnitude. Exp. Clin. Psychopharmacol 10(1), 54-63 (2002).

7. Moore BA, Fiellin DA, Cutter CJ, et al. Cognitive behavioral therapy improves treatment outcomes for prescription opioid users in primary care buprenorphine treatment. J. Subst. Abuse 31(1), 54-57 (2016).

8. Otto MW, Hearon BA, McHugh RK, et al. A randomized, controlled trial of the efficacy of an interoceptive exposure-based CBT for treatment-refractory outpatients with opioid dependence. J. Psychoactive. Drugs 46(5), 402-411 (2014).

9. Pan $\mathrm{S}$, Jiang $\mathrm{H}, \mathrm{Du}$ J, et al. Efficacy of cognitive behavioral therapy on opiate use and retention in methadone maintenance treatment in China: a randomised trial. PloS. one 10(6), e0127598 (2015).

10. Marsden J, Stillwell G, Hellier J, et al. Effectiveness of adjunctive, personalised psychosocial intervention for non-response to opioid agonist treatment: Study protocol for a pragmatic randomised controlled trial. Contemporary. Clinical. Trials 28(1), 36-43 (2017).

11. Campos-Melady M, Smith JE, Meyers RJ, et al. The effect of therapists' adherence and competence in delivering the adolescent community reinforcement approach on client outcomes. Psychol. Addict.Behav 31(1), 117 (2017).
12. Hunter SB, Ayer L, Han B, et al. Examining the sustainment of the AdolescentCommunity Reinforcement Approach in community addiction treatment settings: protocol for a longitudinal mixed method study. Implementation. Science 13 9(1), 104 (2014).

13. Campbell AN, Turrigiano E, Moore $M$, et al. Acceptability of a web-based community reinforcement approach for substance use disorders with treatment-seeking American Indians/Alaska natives. Community Mental Health Journal 51(4), 393-403 (2015).

14. Miller WR, Andrews NR, Wilbourne $P$, et al. A wealth of alternatives: Effective treatments for alcohol problems. In: Miller WR, Heather $\mathrm{N}$, (eds). Treating Addictive Behaviors: Processes of Change. 2nd ed. New York: Plenum Press,. pp 203-16 (1998).

15. Miller WR, Page AC. Warm turkey: Other routes to abstinence. J. Subst. Abuse. Treat 8(1), 227-32 (1991).

16. Sanchez-Craig M, Annis HM, Bornet AR, et al. Random assignment to abstinence and controlled drinking: Evaluation of a cognitive-behavioral program for problem drinkers. J. Consult. Clin. Psychol 52(1), 390403 (1984).

17. Meyers RJ, Smith JE. Clinical guide to alcohol treatment: The Community Reinforcement Approach. New York: Guildford Press,. pp. 20-41 (1995).

18. Petry NM, Simcic F Jr. Recent advances in the dissemination of contingency management techniques: clinical and research perspectives. J. Subst. Abuse. Treat 23(1), 81-86 (2002).

19. Huhn M, Tardy M, Spineli LM, et al. Efficacy of pharmacotherapy and psychotherapy for adult psychiatric disorders: a systematic overview of meta-analyses. JAMA. Psychiatry 71(6), 706-715 (2014).

20. Gutwinski S, Bald LK, Gallinat J, et al. Why do patients stay in opioid maintenance treatment? Substance use \& Misuse 49(6), 694-9 (2014).

21. Czapla M, Simon JJ, Richter B, et al. The impact of cognitive impairment and impulsivity on relapse of alcoholdependent patients: implications for psychotherapeutic treatment. Addiction. Biology Jul 21(4), 873-884 (2016).

22. Torrens M, Fonseca F, Galindo L, et al. Opioid Addiction: Short-and Long-Acting Opioids. Textbook of Addiction Treatment: International Perspectives 467-500 (2015).

23. Day E, Mitcheson L. Psychosocial interventions in opiate substitution treatment services: does the evidence provide a case for optimism or nihilism? Addiction. 2017 Jan 1.

24. Burckhardt CS, Anderson KL. The Quality of Life Scale (QOLS): reliability, validity, and utilization. Health and quality of life outcomes 1(1), 60 (2003).

25. Wampold BE, Flückiger C, Del Re AC, et al. In pursuit of truth: A critical examination of meta-analyses of cognitive behavior therapy. Psychotherapy. Research 27(1), 1432 (2017).

26. Stricker G, Gold JR, editors. Comprehensive handbook of psychotherapy integration. Springer Science \& Business Media; 2013 Jun 29.

27. Fife ST, Whiting JB, Bradford K, et al. The therapeutic pyramid: A common factors synthesis of techniques, alliance, and way of being. J. Marital. Fam. Ther 40(1), 20-33 (2014).

28. Lynch D, Laws KR, McKenna PJ. Cognitive behavioural therapy for major psychiatric disorder: does it really work? A metaanalytical review of well-controlled trials. Psychol. Med 40(1), 9-24 (2010).

29. Conze E. Buddhist thought in India: Three phases of Buddhist philosophy. Routledge; 2013 Oct 16.

30. Shonin E, Van Gordon W, Griffiths MD. Buddhist philosophy for the treatment of problem gambling.

31. Dillard SJ, Dutta M, Sun WS. CultureCentered Engagement With Delivery of Health Services: Co-Constructing Meanings of Health in the Tzu Chi Foundation Through Buddhist Philosophy. Health communication 29(2), 147-56 (2014).

32. Siegel DJ, Siegel MW. Thriving with Uncertainty: Opening the Mind and Cultivating Inner Well-Being Through Contemplative and Creative Mindfulness. The Wiley Blackwell Handbook of Mindfulness. 2014:21-47.

33. West MA, editor. The psychology of meditation: research and practice. Oxford University Press; 2016 Jan 28.

34. Howell J. Revitalised Sufism and the new piety movements in Islamic Southeast Asia. Routledge handbook of religions in Asia. 25(1), 276-92 (2014).

35. Dahl CJ, Lutz A, Davidson RJ. Reconstructing and deconstructing the self: cognitive mechanisms in meditation practice. Trends in cognitive sciences 30(1), 515-23 (2015).

36. Gutierrez D, Fox J, Wood AW. Center, light, and sound: The psychological benefits of three distinct meditative practices. Counseling and Values 60(2), 234-47 (2015).

37. Eifring $\mathrm{H}$. Meditation in Judaism, Christianity and Islam: Technical Aspects of Devotional Practices. Meditation in Judaism, Christianity and Islam: Cultural Histories1-3 (2013). 
Getting Involved In Volunteer Work Could Protect Against Relapse among Detoxified Opiate Patients: A Research Six Months Follow Up Study

38. Joshanloo M. Eastern conceptualizations of happiness: Fundamental differences with western views. J. Happiness. Stud 15(2), 47593 (2014).

39. Watts A. Psychotherapy east \& west. New World Library; 2017 Jan 13.

40. Jung CG. Psychology and Religion Volume 11:
West and East. Routledge; 2014 Dec 18.

41. Zgierska AE, Burzinski CA, Cox J, et al. Mindfulness meditation and cognitive behavioral therapy intervention reduces pain severity and sensitivity in opioid-treated chronic low back pain: pilot findings from a randomized controlled trial. Pain. Medicine
17(10),1865-81 (2016)

42. Lunde LH, Skjøtskift S. Combining mindfulness meditation with cognitive behavior therapy and medication taper for hypnotic-dependent insomnia in older adults: A case study. Clinical. Case. Studies. 14(4), 30720 (2015). 